\title{
Bible Belt Onomastics Revisited
}

\author{
JOHN ALGEO and ADELE ALGEO
}

\begin{abstract}
Alas, for the South! Her names have grown fewer -
She's now not much given to new nomenclature.

[Based on a couplet by J. Gordon Coogler, cited by H. L. Mencken in "The Sahara of the Bozarts"']
\end{abstract}

\begin{abstract}
A 11 things change. Heraclitus said so. And nowhere can we see more clearly the effects of the flow of things than in social matters, where style - at least of a sort - reigns supreme.

In 1947 Thomas Pyles turned his attention to the study of personal names in that part of the nation called the Bible Belt, specifically in Oklahoma, and in 1959 he renewed his interest in the subject in Florida. What Pyles found was an exuberant imagination in the giving of names in the South, an imagination uninhibited by social or religious conventions of the sort that guide naming practice elsewhere in the country. There was, he found, a strong propensity to make up names, some of them remarkably euphonious, others comic - at least to the eyes and ears of an irreverent outsider - but all of them evidence of an onomastic individualism that it is impossible not to admire.

Pyles concluded that a principal reason for the unique naming practices of the Bible Belt was the lack of participation by a clergyman in the naming process. Since, in the antipedobaptist churches that dominate Southern religious life, name giving (at infancy) and baptism (after the age of reason has begun) are two distinct activities and a minister is needed only for the latter, parental imagination suffers no checks in choosing or inventing a name for the baby. And thus we find those fantastic names, "Yada, Telka, Clell, Elissie,"' and all the rest.

Pyles's studies covered a twelve-year period. Now, twenty-four years after he completed them, the time is ripe to take a second look at Bible Belt onomastics. Have the naming customs that Pyles observed been maintained, or has the homogenization of American life reached Southern
\end{abstract}


name giving, wiping out the imaginative names that characterized the region a generation ago? To give at least a partial answer to that question, we have looked at Southern given names, principally in the state of Georgia, drawing names primarily from three sources: a high-school graduation list for 1980, a university graduation list of arts-and-sciences students also for 1980, and the obituary notices for the first half of 1980 from a daily newspaper in a medium-sized Southern town. These three primary sources contain names of persons from different age groups and from somewhat different social groups as well. What they show about personal names in one part of the South today contrasts strikingly with the results of Pyles's studies.

The high school, the university, and the newspaper are all in the same city, a town of about 50,000 population. Most, but not all, of the names from the three sources are of native Georgians or at least of native Southerners. The town, however, being a university community, has a higher educational and cultural level than most cities of comparable size. The names from this community are not necessarily typical of all Bible Belt names today, but the names of the younger persons are doubtless fairly representative of the New South.

All of the names may be taken as formal. Commencement exercises and funeral obsequies are among the most serious events, the most sober and ceremonious of occasions. It will be fair to conclude that the names on these lists are Sunday-go-to-meetin' names. As a rule, they are not merely what a person is called. They are what the person is named. Occasionally the obituary notices give nicknames for men ("Buck," "Dike," "Sing"), but such frivolous bynames are set off by apologetic quotation marks, so they cannot be mistaken for real names.

Names on the high-school graduation list were given to their bearers about 1962. Names on the university graduation list would have been given about 1958, or somewhat before. From the obituary notices, only names of persons who died at or after the age of 40 were taken. Thus they would have been named in 1940 or earlier (many as early as the turn of the century). Thus, although only about four years separate the names of the first two groups, 18 to 60 years separate those of the last two. The three groups will be referred to as high-school students, college students, and older persons.

When a person (chiefly in the two younger groups) could be identified as a foreigner, by a combination of foreign given and surnames, that person's names were omitted from the study. Their number was small.

Some statistics about the names are shown in Table 1, which reports the number of persons and names in the three sources. Eleven men were 
mentioned in the obituary notices by first initial and middle name, rather than by full first name; hence in that group there are fewer first names than persons. The last two columns report the number of tokens (that is, instances of given names) for each group and the number of types (that is, different given names). The totals under the columns for types are of the number of different men's and women's names in the corpus; they do not total the figures above them in the columns, because the figures for the various groups include some of the same names. For example, James occurs in all three groups of men and Mary in all three groups of women, but are counted only once each on the "Total" lines for the columns of types.

All of the given names from all three sources are listed together in the appendix, alphabetically, with the number of instances of each name (tokens of the type) after it. Each distinct spelling is treated as a different name.

Table 1

Number of Names

First Middle Total Names

Persons Names Names Tokens Types

Males

$\begin{array}{lrrrrr}\text { High School } & 157 & 157 & 147 & 304 & 160 \\ \text { College } & 582 & 582 & 567 & 1149 & 387 \\ \text { Older } & 412 & 401 & 182 & 583 & 291 \\ \text { Total } & 1151 & 1140 & 896 & 2036 & 605 \\ & & & & & \\ \text { Females } & & & & & \\ \text { High School } & 163 & 163 & 148 & 311 & 181 \\ \text { College } & 391 & 391 & 369 & 760 & 321 \\ \text { Older } & 379 & 379 & 105 & 484 & 238 \\ \text { Total } & 933 & 933 & 622 & 1555 & 579\end{array}$

The popularity of names in each group is noteworthy. The ten most popular male names for high-school students, in order of decreasing popularity, were David, James, Michael, Robert, Lee, Edward, Richard, Joseph, John, and Charles. The most popular college men's names, again from first to tenth, were John, William, Robert, Michael, James, David, Steven/Stephen, Thomas, Joseph, and Lee. For older men, the ten most popular names, in descending order, were James, John, William, Thomas, Willie, Henry, Robert, George, Charles, and Edward. David accounts for 10 percent of the high-school boys' names, and Edward for 2 
percent of the older men's names - these two being the extremes of frequency for the popular male names. Except for the combination of the spelling variants Steven and Stephen in the college group, each name represents only instances of that form. For example, among older men, both William and its diminutive Willie make the top-ten list.

Leslie Alan Dunkling, in First Names First, reports frequencies of names at various times and in various places in the English-speaking world. All except three of the names above occur also in his lists (pp. 126, 128-29) of the ten most popular male names for the years 1900, 1925, 1950, and 1975. Henry is in the top fifty for the earlier years of the century; Lee and Willie do not occur at all in his lists of popular names. Both of the latter names are distinctly Southern. Lee is found mainly as a middle name (which Dunkling presumably did not include in his counts), and Willie is common only in the older group. Since Dunkling took all except the most recent names from records of university students and Willie is found mainly in the obituary notices, rather than graduation lists, it is possible that there is a class or educational difference in it use. On the whole, however, there is good consistency between the frequencies Dunkling reports and those in the three sources studied here.

Women's names show a somewhat different pattern. The ten most popular female names among high-school students, in descending order, were Lynn, Ann, Louise, Denise, Elaine, Cynthia, Catherine, Mary, Angela, and Diane. The ten most popular names of college women were Ann, Elizabeth, Mary, Lynn, Marie, Susan, Carol, Jean, Margaret, and Deborah/Debra. Among older women, the most frequently occurring names (still in descending order) were Mae, Mary, Willie, Martha, Ruby, Lee, Lula, Elizabeth, Ethel, and Marie. Ann accounts for 8 percent of the college women's names (generally as a middle name), and Marie for less than 2 percent of the older women's names, the other names falling between those extremes in frequency in their groups. Again, except for the conflation of Deborah and Debra in the college group, each name represents only that form. Mary and Marie both make the top-ten list of names of college women, and Mary, Marie, and Mae all make the top-ten list for older women, although historically they are variants of one another.

Dunkling's lists of popular female names (pp. 121, 124-25) are less consistent with the names studied here than were his lists of male names. Of the Southern female names, 9 are in Dunkling's lists of the ten most common names for the four years mentioned above; 9 are in his lists of the fifty most common names; and 6 do not occur in his lists at all. Those 6 are Elaine, Lee, Lula, Mae, Ruby, and Willie. Elaine is from the high-school 
top ten; the others are from the older women's top ten. The first is perhaps too recent, and its popularity may be ephemeral or local; the other five are doubtless regional in their popularity, and the last four are old-fashioned.

Even within the three groups studied here, there is a difference between male and female names in how often they occur. Thus, 3 men's names (James, John, Robert) are in the top ten of all three groups - highschoolers, college students, and older men - whereas 8 names are in the top ten of two groups, and only 5 names are limited to the top ten of a single group. Among the women's names, however, only 1 (Mary) is in all three top-ten lists, 4 names are in the top ten of two groups, and 19 names are found in only one of the top-ten lists.

There is more variety in women's names than in men's. A comparatively small number of male names are of enduring popularity and are used to name a great many men. The comparable stock of female names is much smaller and is not as much or as consistently used. There are perhaps two reasons for this fact.

The naming of males is less free partly because they are often expected to be named for male relatives - fathers, grandfathers, uncles. Just as, in our culture, the surname marks the male line of descent, so a man's given name is likely to tie him to his family. The process of family-binding through given names can be seen in this corpus in two other ways also.

First, the wife's maiden name may be used as a given name. The result is an inconsistent system of matrilineal names. Both men and women have such matrilineal surnames, but men more frequently. The family names are most often used as a middle name, but sometimes even as a first name, for example, Blayne Harris, Talmadge Lucas, Taylor C., Wallace McDuffie, Whitney Boyd or Asberry, Ashbury, Brookin, Hoyt, and McArthur, with no middle name. (All names cited here are used as given names, none as surnames.) In this way family relationships by marriage are remembered and, it may be, boasted of. Family names used as given names may also be from more distant, but distinguished, relatives with whom one wishes to emphasize a connection.

The second way of family-binding is the use of $S r ., J r$. , and numbers $(I, I I, I I I, I V)$. Among high-school boys, 8 percent had some such suffix to their names; 20 percent of the college males did; and 11 percent of the older men. In these cases, of course, an entire name has been repeated the strongest kind of onomastic tie. Thus the repetition of male given names is in keeping with a firm sense of family ties. Its effect, however, is to reduce the number of male names commonly used.

Another reason for the greater variety of female names is that in our culture women are expected and encouraged to have a greater sense of 
stylishness and fashion than are men. Just as the style of women's clothing changes more than that of men's, so does the style of their names. It is a cliche of popular culture that women dressed alike at a party are uncomfortable, whereas men dressed alike are most at their ease. That cliche reflects a real difference between the cultural values the two sexes have learned, which is to be seen also in the tendency to name a boy like other males, but to name a girl distinctively.

In the figures reported in Table 1 and in the name list in the appendix, the greater variety of female names is somewhat obscured by the fact that so many male names, chiefly second names, are family names and each of those tends to be of relatively infrequent use. If the statistics and the appendix reported first names only, the difference between the use of male and female names would be more pronounced. Even so, the difference is present in this corpus. For instance, of all male names, 23 percent are found in both the two younger groups and the older group. Of all female names, however, only 11 percent are found in both the younger and the older groups.

Perhaps the most striking fact about the names in this corpus is the relative scarcity of such exotic names as Pyles noted in his two articles. There are, to be sure, a few choice examples. Among the men's names, Sonuel Lavel has a certain flair to it, as do Cleo, Izzie, Leecil, Sida D., Odennis P., and Lonzire (married to Iunice). Dock Bell and Deacon Ozzie have a pleasantly professional ring to them - one would like to know whether the gentlemen so named found their ways to the cure of body and soul that their first names suggest. Mack, used several times as a man's only given name, has an insouciance to it. Some of the originality in names is in spelling only: Julious and Rueben $B$. The craze for things classical appears in the very traditional Atticus, Titus, and Rex (which last is matched by an English King).

Imaginative women's names include Faithanna, Kimetha, Kira, Mozelle, Nuova, Onie, Ora, Reatha, Ruthine, Texie, Winnette, Bridgenette LaWanda, Cacynthia Lanetta, Dixie Miagene, Ethelyn Kotea, Quinntella Denise, Renata Deann, Sarelda Rhellie, Shelia Amendia, Susan Pheddora, the classical, if apocopated, Tavia Ophelia, and Terri Subrenia. Merry Bee has a bright air about it, as do Robin Dawn and Selena Dawn. It is possible to find such engaging names, for women and men, if one really looks for them - and in fact one need not look very hard. However, it is by no means the case that they are to be found under every bush - and in all likelihood they have never been as prevalent as their distinctiveness might suggest. The really inventive Bible Belt name is, if not quite a thing 
of the past, at least not typical of the Bible Belt today. There are, however, other noteworthy characteristics of these names.

A favored naming pattern for women is a double name, the first name a trochee (especially with the second syllable ending in /i/ or a schwa) and the second name a monosyllable. Older women bear the names Ada Mae, Annie Mae, Annie Maude, Annie Rose, Barbara Ann, Berta Lou, Callie Mae, Cora Lee, Dorothy Lee, Emma Dean, Eula Mae, Gussie Bell, Hattie Sue, Lena Mae, Lillie Mae, Lizzie Lou, Lula Mae, Lucy Mae, Mamie Lou, Martha Jane, Mary Lee, Mary Sue, Minnie Lee, Nellie Mae, Nettie Lou, Pearlie Mae, Ruby Lee, Sadie Ann, Sallie Grace, Sara Kate, Susie Mae, and Virgie Lee.

College women are Amy Ruth, Amy Sue, Barbara Ann, Barbara Nell, Becky Jo, Billie Jean, Carol Ann(e), Carol Jean, Carol Lynn, Cathy Anne, Cathy Lynn, Cheri Ann, Cherie Jeanne, Cheryl Ann, Connie Ann, Crystal Ann, Daphne Lyn, Debbie Lynn, Deborah Ann(e), Deborah Leigh, Deborah Lynn, Debra Ann, Debra Jean, Debra Lee, Debra Nell, Donna Anne, Donna Claire, Donna Jean, Donna Joy, Donna Lynn, Dorothy May, Ellen Rose, Georgia Kim, Helen Blanche, Janice Ann, Janice Lynn, Janis Lynn, Jenni Lane, Joni Beth, Judith Ann, Julie Ann, Julie Lynn, Karen Joyce, Karen Sou, Katherine Lea, Katherine Lynne, Katherine Pearl, Kristi Ann, Laura Anne, Laura Jeanne, Laura Kay, Laurie Lee, Linda Dale, Linda Jo, Linda Ruth, Lisa Anne, Margaret Ann(e), Margaret Beth, Martha Ann, Martha Gayle, Martha Jean, Martha Jo, Martha Lee, Mary Anne, Mary Nell, Mildred Kim, Mindy Jayne, Nancy Jean, Nancy Lynn, Patty Jean, Rhonda Faye, Rhonda Jean, Robin Lynn, Sandra Kay, Sara Ruth, Sarah Ann, Sharon Kay, Susan Claire, Susan June, Susan Lynn, Suzan Jo, Tammy Lou, Tam'ra Jayne, Teri Lynne, Terri Ann, Terri Lynn, Tracey Lynn, Tracy Jane, and Wanda Lynn.

High-schoolers are named Amy Beth, Barbara Nell, Barbara Joyce, Carol Anne, Catherine Ann, Celia Lynne, Cindy Lynn, Daphne Lynn, Debora Kay, Debra Lynn, Debra Sue, Donna Faye, Jodi Lynn, Johna Lyn, Judy Lynn, Katheryn Kay, Kathy Lynne, Laurie Ann, Lisa Ann, Lisa Dawn, Lisa Jayne, Loren Claire, Lori Ann, Lori Lee, Lori Sue, Mary Beth, Mary Lynn, Mitzi Anne, Mona Lynn, Norma Glenn, Olive Sue, Rhonda Lea, Rita Kaye, Robin Dawn, Sandra Faye, Sandra Lee, Shannon Dale, Sherry Ann, Tara Lynn, Tracey Jean, Trudy Lynne, Vera Jean, Wanda Lee, and Wendy Joy.

This pattern of naming appears to be increasing in popularity. Of older women, 12 percent bore such names; of college women, 26 percent; and 
of high-school girls, 28 percent. The pattern can be found in male names too, but at a lesser frequency and without the clear evidence of increasing popularity. Of older men, 14 percent had names with this rhythmic pattern (but without the prominent vowel ending in the first name); of college men, 18 percent; and of high-school boys, 19 percent.

A related female naming pattern that seems to be disappearing is the use of a diminutive masculine name followed by a monosyllable, often clearly feminine. Among the older women are Eddie Maude, Johnnie Lou, Willie Bell, Willie Lee, and Willie Mae. Similar, though with a reversed metrical pattern, is Drew or Drue Willie. College women include Jamie Kay and Neville Jean, but the pattern is not found among the high-school names.

The corresponding male names are what are thought of as "good ol' boy" names. Among the older men are Bobby Ray, Willie Edd, Willie Ben, Willie Clyde, and Willie Fred. Jim Bob, although it lacks the optimum metrical pattern, is definitely "'good ol' boy." Ralph Ned and Henry Jack, however, are less clearly so. Only one college man's name is indisputably “'good ol' boy": Bobby Joe. Jerry Lee, Joe Roy, and Tommy James all try, but fail to make the top grade (Tommy Jim would have had the accolade). There are no incontestably good old names in the highschool crowd. Increasingly, Southern males are named William Robert instead of Billy Bob. It is a great pity.

Another custom in male names that is declining is the commemorative name - commemorative, that is, not of family relationships (a practice that is holding its own) but of some famous person. Older men are named Frank Thomas Jefferson, George Washington, Henry Grady ( a prominent newspaperman, to whom is due the catchphrase "the New South"), Paul Roosevelt (who, with a birthdate of 1904, was doubtless named for the first president of that surname), Robert Lee, Rudell Columbus, Walter Scott, and Woodrow Wilson (born 1916). College men are named for the ever popular Robert Lee and for William Jennings Bryan (the latter, as a $J r$., was carrying on a family tradition doubtless begun at the height of the popularity of the Great Commoner). High-school boys are named Delano (as either first or middle name), Dwight David (almost surely after President Eisenhower), and Laurence Olivier (another $J r$., whose sire perhaps honored Sir Laurence's salad days). Commemorative names, and other aspects of Southern naming customs as well, have been illuminatingly discussed by Philip C. Kolin in his essay "Personal Names in the South."

Women are less likely to have commemorative names. Tara doubtless recalls the O'Hara plantation in Gone with the Wind, the name being quite popular for a variety of uses in northern Georgia. Georgia and Dixie are regionally patriotic. But women are not as a rule named after other famous women. 
Women's names, however, show an ever-growing predilection for the sound $/ 1 /$. Among the older women, 55 percent have names containing the /1/ sound; among college women, 62 percent; and among high-school girls, a whopping 69 percent. The increase is in large measure due to the popularity of names like Lynn and Lee, especially as middle names. But the popularity of those names may be due in turn to a feeling that the liquid $/ 1 /$ is particularly feminine.

Respellings are also typical of women's names. The diminutive ending is fashionably spelled $-i$, rather than $-i e$ or $-y$, as in Joni, Lori, and Terri. Debra reflects the usual pronunciation of the name. Catheren is at most eye-dialect. Lea, Lu, Maree, Sou, Suzan, Syble, Teri, and a good many others are either individualist respellings or in some cases perhaps merely uncertain orthography.

The apportionment of names between the two sexes is not always what might be expected elsewhere in the nation. Cleo, Ladessie, Marion, and Mildred are names of men. (Another such name, not in this corpus but recently in the local news, is LaRamon; the prefix $L a$, as Pyles observed, is not thought of as especially feminine.) On the other hand, as already observed, masculine names are frequently given to women. Willie, usually with a feminine second name, is a favorite for older women. Lee is widely used for both sexes.

Some names are clearly favored as first names, others as middle names. Alan/Allan/Allen, Edward, and Scott are twice more frequent as middle names than as first names. Lee is six times more frequent as a man's middle name. Charles and Mark, on the other hand, are almost four times more frequent as first names. And James and John are very much more frequent as first names. Among women the same sort of distinction exists. For example, Ann(e), Lee, and Lynn(e) are primarily middle names.

Southerners are keenly aware of the implications of names and of Southern customs in name giving. Lewis Grizzard, a columnist for the Atlanta Constitution and an authority on the mores and folkways of the South, wrote a piece on the names of candidates for the 1982 Georgia gubernatorial race. The politicians' given and surnames were Billy Lovett, Bo Ginn, Joe Frank Harris, Jack Watson, Buck Melton, and Norman Underwood. Of their given names, Grizzard wrote:

We got a Billy. I like the name Billy. There is Billy Carter and Billy Martin, and there was a Billie Sol Estes, enchanting fellows all. You might not want to open a liquor store with somebody named Billy, but that doesn't mean he wouldn't make a good governor.

There's Bo. Bo is a good Southern name that will get a man some votes, unless he spells it "beau" and eats quiche.

We like double names in the South. Joe Frank is a wonderful double 
name. It implies a certain gentility and charm. A man named Joe Frank would never do you any harm, and even if he did, he probably could convince you it was for your own good.

"I 'preciate it, Joe Frank," you would say.

Jack. Nothing wrong with Jack, except that it's a little plain. Jack Watson might throw off his citified image if he would come up with a double name, too. Jack Joe Watson. Jack Frank Watson. Jack Joe Frank Watson. It's just a suggestion.

Buck. Now there is a name. Buck Rogers, Buck Belue [a player for the University of Georgia football team] and The Buck Stops Here. I would open a liquor store with a man named Buck; I just wouldn't leave him there alone.

Norman. There have been some great Normans, too. Norman Van Brocklin. Norman Arey, the famous tennis writer. Norman, Oklahoma. I even knew a man who named his bird dog Norman.

And that's the way it is with Bible Belt Onomastics, 1982.

\section{REFERENCES}

Dunkling, Leslie Alan. First Names First. New York: Universe Books, 1977.

Grizzard, Lewis. “At Least One Candidate Has a Bird Dog's Name.' Atlanta Constitution, 24 June 1982, p. A-2/2.

Kolin, Philip C. "Personal Names in the South." Encyclopedia of Southern Culture, ed. Charles Wilson and William Ferris, in press. Chapel Hill: Univ. of North Carolina Press, 1984.

Pyles, Thomas. "Bible Belt Onomastics; or, Some Curiosities of Antipedobaptist Nomenclature." Names 7 (1959) 84-100. Reprint in Thomas Pyles: Selected Essays on English Usage, ed. John Algeo, pp. 152-66. Gainesville: Univ. Presses of Florida, 1979.

---. "Onomastic Individualism in Oklahoma." American Speech 22 (1947) 257-64. Reprint in Thomas Pyles: Selected Essays on English Usage, ed. John Algeo, pp. 144-51. Gainesville: Univ. Presses of Florida, 1979.

\section{APPENDIX}

Men's Names

Aaron 2, Addison 1, Adrian 1, Alan 18, Albert 8, Aldo 1, Alex 2, Alexander 6, Alfred 4, Allan 1, Allen 10, Alton 1, Alver 1, Alvin 7, Alwin 1, Amory 1, Anderson 1, Andrew 17, Anthony 11, Anton 1, Antonio 1, Armstrong 1, Arnold 3, Arthur 5, Artis 1, Asberry 1, Ashbury 1, Atticus 1, Augustus 1, Aurelius 1, Austin 1, Avery 2

Barden 1, Barry 6, Bart 1, Bartow 1, Bealer 1, Bee 1, Bell 1, Ben 2, Benedict 1, Benigno 1, Benjamin 11, Bennie 1, Benson 1, Bernard 5, Berry 1, Bert 2, Berto 1, Bertrand 1, Bevis 1, Billy 1, Blaine 1, Blair 1, Blase 1, Blayne 1, Bob 1, Bobby 4, Bonell 
1, Borden 1, Boyd 2, Brabson 1, Brad 1, Bradford 1, Bradley 1, Braezeale 1, Brent 1, Brevard 1, Brian 8, Brookin 1, Brown 2, Bruce 9, Bryan 6, Bryant 2, Buchman 1, Burns 1, Burton 2, Byron 2

Cabot 1, Calder 1, Calvin 3, Cameron 1, Camper 1, Candler 1, Carey 2, Carl 5, Carlin 1, Carlton 4, Carroll 1, Cary 1, Cecil 1, Cedric 1, Charles 29, Charlie 5, Charlton 1, Chatman 1, Chester 2, Childress 1, Choate 1, Christian 2, Christopher 6, Clarence 4, Clark 1, Clarkson 1, Claude 4, Clay 1, Cleo 1, Cleophas 1, Cleveland 1, Cliff 1, Clifford 5, Clifton 1, Clint 1, Clinton 2, Clyde 7, Cody 1, Coleman 2, Collier 1, Columbus 1, Cooper 2, Cornelius 1, Cornell 1, Craig 5, Cullen 1, Curtis 3

Dale 3, Dan 3, Dana 2, Dane 1, Daniel 15, Darrell 2, Darryl 1, Darryll 1, Darwin 1, Dave 1, Daven 1, David 55, Davis 1, Dawson 1, Deacon 1, Dean 6, Delando 1, Delano 3, Dempsey 1, Denis 1, Dennis 5, DePaul 1, Devoe 1, Dewey 1, Dieon 1, Dillard 1, Dock 1, Don 3, Donald 4, Donarell 1, Donnell 1, Douglas 14, Doyle 2, Drenon 1, Dwight 1

Earl 2, Edd 1, Eddy 1, Edgar 2, Edmond 1, Edward 33, Edwin 10, Elbert 1, Elenor 1, Elford 1, Elihu 1, Ellis 4, Elmer 2, Emmitt 1, Ephy 1, Erby 1, Eric 5, Ernest 6, Errol 1, Ervin 1, Esco 1, Eugene 12, Evart 1, Everett 1

Farris 1, Faulkner 1, Fayne 1, Felton 1, Ferrell 1, Finley 1, Florance 1, Forrest 3, Foster 1, Francis 2, Frank 17, Franklin 4, Frazier 1, Fred 9, Frederic 2, Frederick 3, Fredrick 2, Freeman 3

Gadis 1, Gaffney 1, Gaines 1, Garnett 2, Garry 1, Gary 11, Geddes 1, Gene 2, Geoffrey 1, George 19, Gerald 4, Gerard 2, Geter 1, Gibbs 1, Gilbert 2, Gilmer 1, Glenn 5, Gordon 6, Gould 6, Grady 5, Graham 1, Grant 2, Grauben 1, Greg 1, Gregg 1, Gregory 16, Gridley 1, Grier 1, Griner 1, Grover 1, Gunter 1, Guy 2, Gwynn 1

Hal 2, Hamilton 4, Hamp 1, Hampton 1, Harlan 1, Harold 7, Harris 4, Harrison 4, Harry 6, Hartford 1, Harvey 2, Harward 1, Henry 17, Herbert 6, Herchel 1, Herman 2, Hilliard 1, Hiram 1, Hix 1, Hixson 1, Hoke 3, Holbrooke 1, Hollis 2, Homer 1, Horace 6, Hosch 1, Houston 1, Howard 12, Howell 1, Hoyt 3, Hubert 2, Hugh 3, Hulett 1, Hunter 1 , Hutto 1

Illges 1, Inman 1, Inus 1, Ira 1, Irvin 1, Irwin 1, Isaac 1, Izzie 1

Jack 4, Jackson 5, Jacobs 1, James 67, Jarmal 1, Jarrell 1, Jason 1, Jasper 1, Jay 6, Jefferson 2, Jeffery 4, Jeffrey 9, Jennings 1, Jerl 1, Jerome 3, Jerry 2, Jesse 2, Jeter 1, Jim 3, Jimmy 2, Jiulio 1, Joe 9, Joel 3, John 71, Johnnie 1, Johnny 2, Johnson 1, Jon 2, Jonathan 3, Joseph 33, Juaroud 1, Judson 1, Juergen 1, Julian 1, Julious 1

Karl 1, Karsten 1, Keevin 1, Keith 10, Keller 1, Kelley 1, Kelly 2, Kenloch 1, Kenneth 13, Kent 1, Kevin 7, Kimball 1, King 1, Kirk 1, Kirkwood 1, Kirwin 1, Kurt 1

Ladessie 1, Lamar 4, Lance 4, Landis 1, Lane 1, Langston 1, Larry 5, Latimer 1, Lavel 1, Lawrence 9, Lawton 1, Laymon 1, Leahy 1, Lee 33, Leecil 1, Leland 1, Lemuel 3, Lenton 1, Leo 1, Leon 2, Leonard 1, Leroy 5, Leslie 3, Lester 3, Levan 1, Levi 1, Lewis 8, Lifus 1, Lindsay 2, Lindsey 1, Little 1, Livingston 1, Lloyd 2, Logan 2, Lonnie 3, Lonzire 1, Loran 1, Lorenza 1, Lorenzo 1, Louie 1, Louis 4, Lovett 1, Lowe 1, Lucas 1, Lucius 2, Ludwin 1, Luster 1, Luther 9, Lyles 1, Lyn 1, Lynn 1, Lynwood 2

McArthur 1, McCollum 1, McDuffie 1, Mack 3, McKay 1, McPhail 1, Madison 1, Majette 1, Malcolm 1, Manly 1, Marc 2, Marcus 1, Marion 6, Mark 22, Marshall 3, Martin 4, Marty 1, Mather 1, Matthew 2, Maurice 1, Mazin 1, Meigs 1, Melvin 3, Merlin 2, Michael 49, Michener 1, Milam 1, Milas 1, Mildred 1, Milton 3, Morris 1, Morton 1, Murph 1, Myron 2

Nate 1, Nathan 2, Nathaniel 2, Neal 6, Ned 1, Neel 1, Neil 7, Nelson 1, Nevet 1, Newman 1, Newton 1, Nicholas 1, Noel 2, Norman 3 
Obie 1, Odell 1, Odennis 1, Olando 1, Olin 1, Oliver 3, Olivier 1, Ollen 1, Ollie 1, O'neil 1, Orin 1, Orlando 1, Osborn 1, Oscar 1, Otis 4, Otto 3, Ozzie 1

Parker 2, Parley 1, Patrick 2, Paul 19, Perry 5, Pete 2, Peter 1, Philip 4, Phillip 6, Pinckney 1, Powell 1, Power 1, Pratt 1, Pres 1, Preston 2

Quiller 1, Quinn 1

Rabun 1, Ralph 9, Ramsey 1, Randall 3, Randolph 2, Ray 7, Rayford 1, Raymond 8, Reardon 1, Redmond 1, Reese 2, Reginald 3, Rensselear 1, Reuben 2, Rex 1, Reynolds 1, Richard 28, Ricky 6, Rider 1, Ridgway 1, Ringgold 1, Robert 60, Robinson 1, Rodney 2, Roger 3, Rogers 2, Roland 2, Rolland 1, Ronald 6, Ronnie 1, Roosevelt 1, Roscoe 2, Ross 3, Rowland 1, Roy 6, Royster 1, Rudell 1, Rudolph 1, Reuben 1, Rufus 3, Rusk 1, Russell 10

Salter 1, Sam 1, Samuel 5, Sanford 1, Saye 1, Scott 12, Sean 1, Shade 1, Shelby 1, Sheppard 1, Shipp 1, Sida 1, Sidney 1, Smith 1, Sonuel 1, Spence 2, Spencer 1, Stanley 7, Stanton 1, Stephen 13, Steve 2, Steven 19, Stevens 1, Stevenson 1, Stewart 1, Stuart 4, Sumner 1, Swanson 1, Sylvania 1, Sylvester 2

Taffel 1, Talmadge 2, Talor 1, Taylor 5, Ted 1, Terrell 3, Terry 2, Thad 1, Theodore 4, Thomas 45, Thornton 1, Thurman 1, Tim 1, Timothy 10, Tiner 1, Titus 1, Todd 2, Tom 2 , Tommy 2 , Tony 1 , Tracy 2 , Travis 1 , Turner 1 , Tyrone 1 , Tyson 1

Uth 1

Van 2, Vance 1, Van Noy 1, Vaughan 1, Verlon 1, Vernon 1, Victor 5, Vincent 2

Wade 3, Wallace 3, Wally 1, Walter 16, Walton 2, Warren 3, Washington 1, Waymon 2, Wayne 15, Weathers 1 , Webb 2, Weldon 2, Wells 1, Wendel 1, Wendell 2, Wesley 4, West 1, Weston 1, Whitley 1, Whitney 1, Will 2, Willard 2, William 68, Willie 16, Willis 2, Wilson 5, Winford 1, Winfred 1, Winston 2, Witcher 1, Woodrow 2, Woodson 1 , Wylie 1

Young 1

Zachary 1

\section{Women's Names}

Abby 1, Ada 2, Adair 3, Adams 1, Adeline 1, Agnes 2, Aidan 1, Aileen 1, Aleene 1, Alexis 1, Alfreda 1, Alice 3, Alicia 2, Aline 1, Alison 2, Allen 1, Alline 1, Allison 3, Alma 2, Alpha 1, Alphonza 1, Amanda 2, Amelia 3, Amendia 1, Amy 7, Angela 5, Anita 2, Ann 45, Anna 6, Anne 20, Anneta 1, Annette 2, Annice 1, Annie 4, April 2, Arabella 1, Arlene 1, Ashley 2, Audrey 1

Bancroft 1, Barbara 7, Beatrice 2, Beckley 1, Becky 1, Bee 1, Bell 3, Bena 1, Bernice 3, Berta 2, Bertha 2, Bessie 1, Beth 6, Betty 1, Beulah 1, Beulla 1, Billie 1, Birdell 1, Blanch 1, Blanche 2, Bland 1, Blannie 1, Bonnie 2, Bonny 1, Brandy 1, Brenda 1, Bridgenette 1, Brooks 1, Bryan 1, Buris 1, Burnett 1

Cacynthia 1, Caldwell 1, Callie 3, Candace 2, Candida 1, Carleen 1, Carlile 1, Carmen 1, Carol 20, Caroline 4, Carolyn 6, Carroll 1, Cassandra 1, Catarina 1, Catheren 1, Catherine 9, Cathern 1, Cathey 1, Cathleen 2, Cathy 4, Cecilia 1, Celia 2, Charlene 2, Charlotte 1, Cheri 1, Cherie 1, Cheryl 1, Chisholm 1, Christine 1, Christy 1, Cindy 3, Clair 1, Claire 3, Clara 2, Claudette 1, Claudia 1, Cleo 1, Cole 1, Colettle 1, Collette 1, Collis 1, Condie 1, Conner 1, Connie 2, Constance 2, Constanza 1, Cora 1, Coral 1, Corene 1, Cornelia 3, Crystal 1, Cynthia 15

Daisy 2, Dale 4, Dana 2, Danielle 2, Daphne 2, Darlene 1, Darnall 2, Dawn 4, Deann 1, Debbie 1, Debora 1, Deborah 8, Debra 8, Deidre 1, Delius 1, Dell 1, Delois 1, Delores 1, Deneise 1, Denisa 1, Denise 15, Dessemer 1, De'vera 1, Diana 1, Diane 12, Dianna 1, 
Dianne 1, Dixie 1, Donna 6, Doris 2, Dorothy 3, Dovie 1, Drew 1, Drucilla 2, Drue 2 Edda 1, Eddie 1, Edith 1, Edna 5, Effa 1, Eileen 1, Elaine 16, Eleanor 2, Eleonora 1, Elizabeth 35, Ella 3, Ellen 8, Ellie 3, Ellinor 1, Eloise 2, Elsie 1, Elza 1, Emily 2, Emma 5, English 1, Erah 1, Estella 1, Estelle 4, Ester 1, Esther 1, Ethel 6, Ethelyn 1, Etta 1, Eugenia 2, Eula 4, Eulalia 2, Eunice 1, Eva 2, Evelyn 1

Faithanna 1, Fannie 3, Farah 1, Faye 5, Felicia 1, Fern 1, Flora 3, Florella 1, Florence 2, Floretta 1, Florrye 1, Fowler 1, Frances 13, Frederica 1, Frederick 1

Gail 3, Gayle 2, Genell 1, Georgia 2, Georgie 1, Geraldine 1, Gertrude 3, Gladys 2, Glenn 1, Gloria 2, Goulding 1, Grace 6, Gradine 1, Gray 1, Gussie 1, Gwendolyn 3

Hammond 1, Harriet 3, Harriett 1, Hattie 1, Hazel 2, Heather 1, Heidi 2, Helen 8, Helene 2, Henrietta 1, Hickok 1, Hilda 2, Holly 1, Hoyle 1, Hurt 1

Ida 3 , Ilonia 1 , Ima 1 , Imogene 1 , Ina 2 , Ines 1 , Inez 1 , Irene 4 , Iris 1

Jacqueline 4, Jamie 2, Jan 1, Jane 9, Janet 2, Janice 3, Janie 1, Janis 2, Jayne 3, Jean 16 , Jeanette 1 , Jeanne 3 , Jeannine 1 , Jenney 1 , Jenni 1 , Jennie 2 , Jennifer 6 , Jenny 1 , Jerome 1, Jessie 4, Jewell 2, Jill 2, Jimmie 1, Jo 4, Joan 4, Joanna 1, Joanne 1, Jodi 1, JoEllen 1, Johna 1, Johnnie 1, Joni 1, Josephine 5, Joy 6, Joyce 4, Juanita 3, Judith 3, Judy 4, Juli 1, Julia 8, Julie 4, Juliet 1, June 3

Karen 8, Kate 1, Kateri 1, Katherine 3, Katheryn 1, Kathleen 6, Kathryn 6, Kathy 2, Kay 7, Kaye 1, Keller 1, Kelly 1, Kenya 1, Kim 2, Kimberley 2, Kimberly 3, Kimetha 1, Kira 1, Kotea 1, Kristen 1, Kristi 1

La Boon 1, Ladene 1, LaFaye 1, Landrum 1, Lane 2, Lanetta 1, Lannie 1, LaRue 1, Lattke 1, Laura 10, Lauren 1, Laurie 3, Lavada 1, Laverne 1, LaWanda 2, Layne 1, Lea 3, Leanna 1, LeAnne 1, Lee 14, LeeAnne 1, Leen 1, Leigh 4, Leila 1, Lela 1, Lena 2, Lenita 1, Leonora 1, Leslea 1, Lesley 1, Leslie 3, Letha 1, Lettie 1, Levie 1, Lilliam 1, Lillian 4, Lillie 4, Linda 12, Lisa 11, Lisette 1, Lizzie 3, Lois 5, Lola 1, Loren 1, Lorenda 1, Loretta 1, Lori 4, Lorraine 3, Lou 6, Louise 22, Lourene 1, Lu 1, Lucile 1, Lucille 3, Lucy 6, Lula 7, Lurine 1, Lydia 1, Lyn 3, Lynda 1, Lynn 32, Lynne 6

Mabel 1, Mable 2, Madie 1, Mae 24, Maggie 1, Malinda 1, Mamie 4, Mandy 1, Manuela 1, Marcie 1, Maree 1, Margaret 17, Margarette 1, Margarie 1, Marguerite 1, Margery 1, Maria 5, Marian 1, Marie 28, Marilea 1, Marilyn 3, Marlene 2, Marshall 1, Martha 16, Martine 1, Martye 1, Mary 45, Matilda 1, Mattie 3, Maude 2, Maureen 2, Mavis 1, Maxine 2, May 2, Mazie 1, Melanie 3, Melinda 1, Melissa 3, Melody 1, Mendie 1, Merry 1, Miagene 1, Michele 2, Michell 1, Michelle 3, Mildred 4, Miller 1, Mindy 1, Minnie 3, Miriam 2, Mitzi 1, Mona 2, Monica 1, Montie 1, Montine 2, Mossie 1, Mozell 1, Mozelle 2, Myrna 1

Nancy 8, Naomi 2, Natalie 1, Nell 6, Nelle 1, Nellie 2, Nettie 1, Neville 1, Newton 1, Noel 1, Nora 2, Norma 2, Nuova 1

Ofea 1, Olive 1, Ollie 1, Oneita 1, Onie 1, Opal 1, Ophelia 2, Ora 3, Orene 1, Ottie 1

Paige 2, Pamela 3, Patrice 1, Patricia 6, Patterson 1, Patti 1, Patty 1, Paula 5, Pauline

4, Pearl 4, Pearlie 1, Penelope 1, Penrod 1, Pheddora 1, Phyllis 3, Powell 1 Quinntella 1

Rachel 1, Ramona 1, Reatha 1, Reba 1, Rebecca 6, Reese 1, Regina 1, Reid 1, Renata 1, Renee 3, Rhellie 1, Rhonda 4, Rickman 1, Rita 3, Roberta 1, Robin 5, Rosa 2, Rose 2, Rosena 1, Ross 1, Roxanne 1, Roxie 1, Ruby 7, Rumel 1, Ruth 6, Ruthine 1

Sadie 1, Sallie 3, Sandra 3, Sara 4, Sarah 7, Saralyn 1, Sarelda 1, Saucier 1, Scales 1, Scott 2, Scoville 1, Selena 1, Selina 1, Shannon 1, Sharon 6, Shelia 1, Shelley 1, Sherri 1, Sherrian 1, Sherry 1, Sheryl 2, Shirley 1, Sonin 1, Sou 1, Stanley 1, Stella 1, Stephanie 1, Subrenia 1, Sue 11, Sunie 1, Susan 20, Susie 5, Suzan 1, Suzanne 6, Syble 1 Tammie 1, Tammy 1, Tam'ra 1, Tara 1, Tavia 1, Taylor 1 , Teresa 8 , Terese 1 , Teri 1 , 
Terri 4, Texie 1, Thelma 3, Theresa 4, Toni 2, Tracey 2, Tracy 1, Tressa 1, Trudy 1 Valerie 1, Vanessa 1, Velinda 1, Venette 1, Vera 2, Vernessia 1, Vickers 1, Vicki 1, Vicky 1, Victoria 4, Viola 3, Virgie 1, Virginia 6, Vitina 1, Vivian 2

Wakefield 1, Wanda 3, Wasley 1 , Webster 1 , Wells 1 , Wendy 2 , White 1 , Wilhelmina

1, Willie 11, Wilma 2, Winnette 1

Yvette 3, Yvonne 1

Zandra 1

University of Georgia

Athens, Georgia 